\title{
The challenge of the multifaceted prognosis in the older people and the Multidimensional Prognostic Index
}

\author{
Francesco Mattace-Raso ${ }^{1} \cdot$ Alberto Pilotto $^{2,3}$
}

Published online: 23 February 2021

(c) European Geriatric Medicine Society 2021

An accurate assessment of prognosis may have a crucial role in clinical decision making of the older people [1]. An increasing body of evidences indicates that the prognosis of older patients is strongly related to the presence of concomitant diseases and to the degree of physical, cognitive, biological, and social impairment [2].

The Comprehensive Geriatric Assessment (CGA) is the tool of choice to effectively explore these domains of health, especially in the functionally compromised and frail older subject [3]. The Multidimensional Prognostic Index (MPI) is a product of the CGA, that uses a mathematic algorithm including information about eight domains relevant for the global assessment of the older subjects (i.e., functional and cognitive status, nutrition, mobility and risk of pressure sores, multimorbidity, polypharmacy and co-habitation), to generate a numeric score (or index), between 0 and 1 , that expresses the global risk of multidimensional impairment [4]. In this sense, we can say that MPI is able to translate the clinical evaluation of the CGA in a score that can accurately predict overall mortality and other negative outcomes, and therefore, be used as prognostic tool in older people.

The MPI was initially developed and validated as a prognostic index predicting mortality in hospitalized older patients [5]. A modified MPI, including the mini nutritional assessment short-form (MNA-SF), showed similar degree of accuracy as the original MPI, but could be completed in around $20 \mathrm{~min}$ [6]. Other versions of the MPI have been developed and validated in large populations

Alberto Pilotto

alberto.pilotto@galliera.it

1 Division of Geriatric Medicine, Department of Internal Medicine, Erasmus MC University Medical Center, Rotterdam, The Netherlands

2 Geriatric Unit, Department of Geriatric Care, Orthogeriatrics and Rehabilitation, EO Galliera Hospital, Genova, Italy

3 Department of Interdisciplinary Medicine, University of Bari, Bari, Italy of community-dwelling older subjects who underwent a standard CGA to be admitted to public health facilities, i.e., homecare services or nursing homes [7] as well as in population-based cohorts of older subjects living at home or in an institution in Sweden [8], Italy [9], Ireland [10] and in the United States within the framework of the osteoarthritis initiative (OAI) [11]. All these studies confirmed the accuracy of the MPI in predicting life expectancy [8, 9] and the risk of hospitalization [8] during long periods of follow-up (from 12 to over 15 years) as well as the long-term risk of incident depression [10] and falls [11]. Moreover, in the context of the EU co-funded project EFFICHRONIC a self-administered version of the MPI (SELFY_MPI) was developed and validated as screening tool for communitydwelling patients with chronic diseases (or their caregivers) candidate to be managed through a self-management program [12, 13]; a short-form version of the SELFY_MPI was developed for older patients who attended an ambulatory visit by their general practitioners [14]. Very recently, a telephone-administered version of the MPI (TELE-MPI) was also developed and validated for remote monitoring of older adults during COVID-19 pandemic [15].

In the current issue of Eur Geriatr Med, Hansen et al. evaluated the predictive value of a previously validated [16] record-based MPI including data of the inpatient's electronic medical records to assess multidimensional frailty in a large cohort of 1.190 medical inpatients aged $\geq 75$ years [17]. The results demonstrated that the record-based MPI, assessed at discharge in hospitalized older patients, accurately predicted post-discharge mortality (after 90-days and 1 year) and hospital readmissions in a dose-dependently manner; moreover the MPI value was associated with the hospital length-of-stay. These findings further support the concept that the MPI, although derived from different assessment scales in different settings (provided that these scales accurately explore all the domains linked to the multidimensional impairment), is able to express numerically the global health and functions to implement a multidimensional approach to 
the assessment of frailty in older people [18]. Indeed, the MPI is currently one of the most commonly used tools for evaluating frailty, both in primary care and hospital settings [19].

Large multicenter studies including more than 60.000 older subjects in different settings showed that the CGAbased MPI is able to: (1) predict mortality more accurately than other frailty instruments based on both phenotypic and multiple-deficits models [20]; (2) predict in-hospital length of stay [21, 22]; (3) to monitor changes of health and functional status during hospitalization [23, 24]; (4) identify those older patients who will be admitted to homecare services, nursing homes and/or re-hospitalized 1 year after discharge from the hospital [25]; (5) inform about healthrelated quality of life in older patients admitted to emergency department [26]; (6) predict burden on healthcare resources [27] and successful application for disability social benefits in older people with cognitive decline [28].

During the last 10 years, the MPI has been successfully applied in older patients with specific acute diseases [4, 18], i.e., gastrointestinal bleeding [29], pneumonia [30], heart failure [31], transient ischemic attach [32], and chronic disorders including dementia [33], late-life depression [34], liver cirrhosis [29], diabetes mellitus [35], chronic kidney disease [36] and cancer [37]. In all these studies, MPI resulted a well-calibrated prognostic tool with a good accuracy that is maintained both at short- and long-term followup showing a very high score in terms of validity, reliability and feasibility for the management of older persons in clinical practice $[4,18,38]$.

Recently, the European project MPI_AGE explored in deep the role of the CGA-based MPI as tool for driving clinical decisions in frail older adults with multimorbidity [4, 39]. In this context, several clinical studies evaluated the appropriateness of "critical" treatments in geriatric setting, such as statins in secondary prevention of diabetes mellitus [40] and coronary artery disease [41], anticoagulants in atrial fibrillation [42], antidementia drugs in late-life dementia [43] or transcatheter aortic valve implantation (TAVI) in older patients with aortic stenosis [44, 45] and enteral tube feeding intervention in malnourished hospitalized older patients [46].

Finally, very recently independent studies demonstrated that the MPI could also extend to specific areas for personalized therapies such as for guiding immunotherapy in patients with advanced malignancies [47] or helping physicians in clinical decisions for older adults with chronic kidney disease on conservative treatment or renal replacement (hemodialysis or peritoneal dialysis) [48], or with acute myocardial infarction who underwent a percutaneous coronary intervention (PCI) [49], and in older patients candidate to elective surgery for colon-rectal cancer [50] or to non-invasive ventilation for acute respiratory failure [51]. Promising findings from all these studies showed that in older adults the multidimensional approach warrants better clinical decisions (i.e., to treat or not to treat) depending on degree of multidimensional impairment of the subject. For these reasons the implementation of new MPI versions that facilitate the calculation of the MPI directly from information included in the clinical records such as the record-based MPI [16], as reported in the article of Hansen et al. [17], should be recommended to physicians to enhance the diffusion in clinical practice of the multidimensional approach to the frail older patient [18]. This seems to be particularly important during the recent COVID-19 pandemic in which an accurate prognosis, as improved by including physical and cognitive functioning information to age and comorbidities, should be the driver for the clinical decisions in the older patients, beyond the chronological age [52]. A multicenter prospective study on the potential usefulness of the MPI in hospitalized older patients with COVID-19 is ongoing in the frame of the Special Interest Group on the Comprehensive Geriatric Assessment (SIG-on-CGA) of the European Geriatric Medicine Society (EuGMS) to clarify this issue [53].

\section{Compliance with ethical standards}

Conflict of interest Authors declared no conflit of interest.

Ethical approval No ethical approval statement is required for this editorial article.

Informed consent No informed consent statement is required for this editorial article.

\section{References}

1. Gill TM (2012) The central role of prognosis in clinical decision making. JAMA 307:199-200

2. Yourman LC, Lee SJ, Schonberg MA, Widera EW, Smith AK (2012) Prognostic indices for older adults: a systematic review. JAMA 307:182-192

3. Pilotto A, Cella A, Pilotto A, Daragjati J, Veronese N, Musacchio $\mathrm{C}$ et al (2017) Three decades of comprehensive geriatric assessment: evidence coming from different healthcare settings and specific clinical conditions. J Am Med Dir Assoc 18:e191-192

4. Cruz-Jentoft AJ, Daragjati J, Fratiglioni L, Maggi S, Mangoni AA, Mattace-Raso F et al (2020) Using the multidimensional prognostic index (MPI) to improve cost-effectiveness of interventions in multimorbid frail older persons: results and final recommendations from the MPI_AGE European Project. Aging Clin Exp Res 32(5):861-868

5. Pilotto A, Ferrucci L, Franceschi M, D’Ambrosio LP, Scarcelli C, Cascavilla L et al (2008) Development and validation of a multidimensional prognostic index for one-year mortality from comprehensive geriatric assessment in hospitalized older patients. Rejuvenation Res 11:151-161 
6. Sancarlo D, D'Onofrio G, Franceschi M, Scarcelli C, Niro V, Addante $\mathrm{F}$ et al (2011) Validation of a modified multidimensional prognostic index (m-MPI) including the mini nutritional assessment short-form (MNA-SF) for the prediction of one-year mortality in hospitalized elderly patients. J Nutr Health Aging 15:169-173

7. Pilotto A, Gallina P, Fontana A, Sancarlo D, Bazzano S, Copetti $M$ et al (2013) Development and validation of a multidimensional prognostic index for mortality based on a standardized multidimensional assessment schedule (MPI-SVaMA) in communitydwelling older subjects. J Am Med Dir Assoc 124:287-292

8. Angleman SB, Santoni G, Pilotto A, Fratiglioni L, Welmer AK, on behalf of the MPI_AGE Project Investigators (2015) Multidimensional prognostic index in association with future mortality and number of hospital days in a population-based sample of older adults: results of the EU funded MPI_AGE project. PLoS ONE. https://doi.org/10.1371/journal.pone.0133789 (pages 1/11)

9. Pilotto A, Veronese N, Siri G, Bandinelli S, Tanaka T, Cella A, Ferrucci L (2020) Association between the multidimensional prognostic index and mortality over 15 years of follow-up in the Inchianti study. J Gerontol A Biol Sci Med Sci. https://doi. org/10.1093/gerona/glaa237

10. Veronese N, Koyanagi A, Smith L, Solmi M, Senesi B, Cella A, Pilotto A (2020) Relationship between multidimensional prognostic index and incident depressive symptoms in older people: findings from the Irish longitudinal study on ageing. Int J Geriatr Psychiatry. https://doi.org/10.1002/gps.5331

11. Veronese N, Siri G, Cella A, Maggi S, Zigoura E, Puntoni M, Smith L et al (2020) The multidimensional prognostic index predicts falls in older people: an 8-year longitudinal cohort study of the osteoarthritis initiative. J Am Med Dir Assoc 21(5):669-674

12. Pilotto A, Veronese N, Quispe K, Zora S, Boone A, Puntoni M et al (2019) Development and validation of a self-administered multidimensional prognostic index (SELFY-MPI) to predict negative health outcomes in community-dwelling persons. Rejuvenation Res 22(4):299-305

13. Zora S, Veronese N, Ferri A, Boone ALD, Pisano Gonzalez M, Pers Y-M, Raat H et al (2019) Implementation of the SELFYMPI in five European countries: a multicenter international feasibility study. Geriatric Care 5(3):8502. https://doi.org/10.4081/ gc.2019.8502

14. Cella A, Ferrari A, Rengo G, Solfrizzi V, Veronese N, Puntoni M et al (2020) Agreement of a short form of the self-administered multidimensional prognostic index (SELFY-MPI-SF): a useful tool for the self-assessment of frailty in community-dwelling older people. Clin Interv Aging 15:493-499

15. Custodero C, Senesi B, Pinna A, Floris A, Vigo M, Fama M et al (2020) Validation of telephone-administered version of the multidimensional prognostic index (TELE-MPI) for remote monitoring of older adults during COVID-19 pandemic. Eur Geriatr Med 11(Suppl 1):S107-108

16. Hansen TK, Damsgaard EM, Shahla S, Bruun JM, Gregersen M (2020) A reliable and record-based frailty assessment method for older medical inpatients. Eur Geriatr Med 11:803-812. https:// doi.org/10.1007/s41999-020-00345-8

17. Hansen TK, Shahla S, Damsgaard EM, Bossen SR, Bruun JM, Gregersen M (2021) Mortality and readmission risk can be predicted by the record-based multidimensional prognostic index: a cohort study of premorbid medical inpatients older than 75 years. Eur Geriatr Med (in press)

18. Pilotto A, Custodero C, Maggi S, Polidori MC, Veronese N, Ferrucci $\mathrm{L}$ (2020) A multidimensional approach to frailty in older people. Ageing Res Rev 60:101047. https://doi.org/10.1016/j. arr.2020.101047

19. Dent E, Martin FC, Bergman H, Woo J, Romero-Ortuno R, Walston JD (2019) Management of frailty: opportunities, challenges, and future directions. Lancet 394:1376-1386. https ://doi.org/10.1016/S0140-6736(19)31785-4

20. Pilotto A, Rengo F, Marchionni N, Sancarlo D, Fontana A, Panza F, Ferrucci L, on behalf of the FIRI-SIGG Study group (2012) Comparing the prognostic accuracy for all-cause mortality of the frailty instruments: a multicentre 1-year follow-up in hospitalized older patients. PLoS ONE 7(1):e29090 (1-9). https ://doi.org/10.1371/journal.pone.0029090

21. Volpato S, Bazzano S, Fontana A, Ferrucci L, Pilotto A, on behalf of the MPI-TriVeneto Study Group (2015) Multidimensional prognostic index predicts mortality and length of stay during hospitalization in the older patients: a multicenter prospective study. J Gerontol A Biol Sci Med Sci 70(3):323-329

22. Pilotto A, Sancarlo D, Pellegrini F, Rengo F, Marchionni N, Volpato S, Ferrucci L, on behalf of the FIRI-SIGG Study Group (2016) The multidimensional prognostic index predicts in-hospital length of stay in older patients: a multicenter prospective study. Age Ageing 45:90-96

23. Volpato S, Daragjati J, Simonato M, Fontana A, Ferrucci L, Pilotto A (2016) Change in the multidimensional prognostic index score during hospitalization in older patients. Rejuvenation Res 19(3):244-251

24. Pickert L, Meyer AM, Becker I, Heeß A, Noetzel N, Brinkkötter $P$ et al (2021) Role of a multidimensional prognosis in-hospital monitoring for older patients with prolonged stay. Int J Clin Pract 6:e13989. https://doi.org/10.1111/ijcp.13989

25. Pilotto A, Veronese N, Daragjati J, Cruz-Jentoft AJ, Polidori MC, Mattace-Raso F et al (2019) Using the multidimensional prognostic index to predict clinical outcomes of hospitalized older persons: a prospective, multicenter, international study. J Gerontol A Biol Sci Med Sci 74:1643-1649. https://doi. org/10.1093/gerona/gly239

26. Rarek MP, Meyer AM, Pickert L, Pilotto A, Benzing T, Burst V, Polidori MC (2020) The prognostic signature of health-related quality of life in older patients admitted to the emergency department: a 6-month follow-up study. Aging Clin Exp Res. https://doi.org/10.1007/s40520-020-01732-8

27. Meyer AM, Becker I, Siri G, Brinkkötter PT, Benzing T, Pilotto A, Polidori MC (2019) New associations of the multidimensional prognostic index. Z Gerontol Geriatr 52(5):460-467

28. Senesi B, Prete C, Siri G, Pinna A, Giorgeschi A, Veronese N et al (2020) Multidimensional prognostic index (MPI) predicts successful application for disability social benefits in older people. Aging Clin Exp Res. https://doi.org/10.1007/s40520-02001694-x

29. Pilotto A, Addante F, D’Onofrio G, Sancarlo D, Ferrucci L (2009) The comprehensive geriatric assessment and the multidimensional approach. A new look at the older patient with gastroenterological disorders. Best Pract Res Clin Gastroenterol 23:829-837

30. Pilotto A, Addante F, Ferrucci L, Leandro G, D'Onofrio G, Corritore $\mathrm{M}$ et al (2009) The multidimensional prognostic index predicts short- and long-term mortality in hospitalized geriatric patients with pneumonia. J Gerontol A Biol Med Sci 64:880-887

31. Pilotto A, Addante F, Franceschi M, Leandro G, Rengo G, D'Ambrosio P et al (2010) A multidimensional prognostic index (MPI) based on a comprehensive geriatric assessment predicts short-term mortality in older patients with heart failure. Circ Heart Fail 3:14-19

32. Sancarlo D, Pilotto A, Panza F, Copetti M, Longo MG, D'Ambrosio P et al (2012) A multidimensional prognostic index (MPI) based on a comprehensive geriatric assessment predicts short- and long-term all-cause mortality in older hospitalized patients with transient ischemic attack. J Neurol 259:670-678

33. Gallucci M, Battistella G, Bergamelli C, Spagnolo P, Mazzuco S, Carlini A et al (2014) Multidimensional prognostic index in a cognitive impairment outpatient setting: mortality and 
hospitalizations. The Treviso Dementia (TREDEM) study. J Alzheimers Dis 42:1461-1468

34. Pilotto A, D'Onofrio G, Panza F, Copetti M, Cascavilla L, Paris F et al (2012) Treatment of late-life major depressive disorder with selective serotonin reuptake inhibitors improves the multidimensional prognostic index. J Clin Psychopharmacol 32:726-729

35. Maggi S, Noale M, Pilotto A, Tiengo A, Cavallo Perin P, Crepaldi G, for the Metabolic Working Group (2013) The METABOLIC study: multidimensional assessment of health and functional status in older patients with type 2 diabetes taking oral antidiabetic treatment. Diabetes Metab 39(3):236-243. https://doi. org/10.1016/j.diabet.2013.02.003

36. Pilotto A, Sancarlo D, Aucella F, Fontana A, Addante F, Copetti $M$ et al (2012) Addition of the multidimensional prognostic index to the estimated glomerular filtration rate improve prediction of long-term all-cause mortality in older patients with chronic kidney disease. Rejuvenation Res 15(1):82-88

37. Giantin V, Falci C, De Luca E, Valentini E, Iasevoli M, Siviero $\mathrm{P}$ et al (2018) Performance of the multidimensional geriatric assessment and multidimensional prognostic index in predicting negative outcomes in older adults with cancer. Eur J Cancer Care. https://doi.org/10.1111/ecc.12585

38. Warnier RM, van Rossum E, van Velthuijsen E, Mulder WJ, Schols JM, Kempen GI (2016) Validity, reliability and feasibility of tools to identify frail older patients in inpatient hospital care: a systematic review. J Nutr Health Aging 20:218-230

39. Pilotto A, Sancarlo D, Polidori MC, Cruz-Jentoft AJ, MattaceRaso F, Paccalin M et al (2015) The MPI_AGE European project: using multidimensional prognostic indices (MPI) to improve costeffectiveness of interventions in multimorbid frail older persons. Background, aim and design. Eur Geriatr Med 6:184-188

40. Pilotto A, Panza F, Copetti M, Simonato M, Sancarlo D, Gallina P, Strandberg T, on behalf of the MPI_AGE Project Investigators (2015) Statin treatment and mortality in community-dwelling frail older patients with diabetes mellitus: a retrospective observational study. PLoS ONE. https://doi.org/10.1371/journal.pone.0130946

41. Pilotto A, Gallina P, Panza F, Copetti M, Cella A, Cruz-Jentoft A et al (2016) Relation of statin use and mortality in communitydwelling frail older patients with coronary artery disease. Am J Cardiol 118(11):1624-1630

42. Pilotto A, Gallina P, Copetti M, Pilotto A, Marcato F, Mello AM et al (2016) Warfarin treatment and all-cause mortality in community-dwelling older adults with atrial fibrillation: a retrospective observational study. J Am Geriatr Soc 64:1416-1424

43. Pilotto A, Polidori MC, Veronese N, Panza F, Arboretti Giancristofaro R, Pilotto A, on behalf of Multidimensional Prognostic Index (MPI)_Age Project Investigators (2018) Association of antidementia drugs and mortality in community-dwelling frail older patients with dementia: the role of mortality risk assessment. J Am Med Dir Assoc 19:162-168

44. Bureau ML, Liuu E, Christiaens L, Pilotto A, Mergy J, Bellarbre $F$ et al (2017) Using a multidimensional prognostic index (MPI) based on comprehensive geriatric assessment (CGA) to predict mortality in elderly undergoing transcatheter aortic valve implantation. Int J Cardiol 236:381-386

45. van Mourik MS, van der Velde N, Mannarino G, Thibodeau MP, Masson JB, Santoro G et al (2019) Value of a comprehensive geriatric assessment for predicting one-year outcomes in patients undergoing transcatheter aortic valve implantation: results from the CGA-TAVI multicentre registry. J Geriatr Cardiol 16:468-477

46. Veronese N, Cella A, Cruz-Jentoft AJ, Polidori MC, Mattace-Raso F, Paccalin M et al (2020) Enteral tube feeding and mortality in hospitalized older patients: a multicenter longitudinal study. Clin Nutr 39(5):1608-1612

47. Sbrana A, Antognoli R, Pasqualetti G, Linsalata G, Okoye C, Calsolaro V et al (2020) Effectiveness of multi-prognostic index in older patients with advanced malignancies treated with immunotherapy. J Geriatr Oncol 11(3):503-507. https://doi.org/10.1016/j. jgo.2019.09.010

48. Lai S, Amabile MI, Mazzaferro S, Imbimbo G, Mitterhofer AP, Galani A et al (2020) Association between multidimensional prognostic index and hospitalization and mortality among older adults with chronic kidney disease on conservative or on replacement therapy. J Clin Med 9(12):3965. https://doi.org/10.3390/jcm91 23965

49. Cammalleri V, Bonanni M, Bueti FM, Matteucci A, Cammalleri L, Stifano G et al (2020) Multidimensional prognostic index (MPI) in elderly patients with acute myocardial infarction. Aging Clin Exp Res. https://doi.org/10.1007/s40520-020-01718-6

50. Pata G, Bianchetti L, Rota M, Marengoni A, Chiesa D, Cassinotti E et al (2020) Multidimensional prognostic index (MPI) score has the major impact on outcome prediction in elderly surgical patients with colorectal cancer: the FRAGIS study. J Surg Oncol. https://doi.org/10.1002/jso.26314

51. Custodero C, Gandolfo F, Cella A, Cammalleri LA, Custureri $\mathrm{R}$, Dini S et al (2021) Multidimensional prognostic index (MPI) predicts non-invasive ventilation failure in older adults with acute respiratory failure. Arch Gerontol Geriatr 94:104327. https://doi. org/10.1016/j.archger.2020.104327

52. Aliberti MJR, Avelino-Silva TJ (2021) Beyond age. Improvement of prognostication through physical and cognitive functioning for nursing home residents with COVID-19. JAMA Intern Med. https ://doi.org/10.1001/jamainternmed.2020.8190

53. Custodero C, Cella A, Veronese N, Azzini M, Fimognari F, Mattace-Raso $\mathrm{F}$ et al (2020) The multidimensional prognostic index (MPI) for the prognostic stratification of hospitalized older patients with COVID-19: a prospective multicenter observational cohort study. Objectives, study design and expected outcomes. (MPI_COVID-19). Geriatric Care 6:9038

Publisher's Note Springer Nature remains neutral with regard to jurisdictional claims in published maps and institutional affiliations. 